\title{
The aptamer ARCI779 is a potent and specific inhibitor of von Willebrand Factor-mediated ex vivo platelet function in ST-elevation and non-ST-elevation acute myocardial infarction
}

\author{
Alexander O Spiel ${ }^{1}$, Florian B Mayr ${ }^{1}$, Nathalie Ladani ${ }^{1}$, Patricia G Merlino ${ }^{2}$, \\ Robert Schaub², Jim Gilbert ${ }^{2}$ and Bernd Jilma*1
}

\author{
Address: ${ }^{1}$ Department of Clinical Pharmacology, Medical University of Vienna, 1090 Vienna, Austria and ${ }^{2}$ Archemix Corporation, Cambridge, MA \\ 02140, USA \\ Email: Bernd Jilma* - bernd.jilma@meduniwien.ac.at \\ * Corresponding author
}

from 14th Scientific Symposium of the Austrian Pharmacological Society (APHAR)

Innsbruck, Austria. 2I-22 November 2008

Published: 5 November 2008

BMC Pharmacology 2008, 8(Suppl I):A54 doi:I0.1 186/I47I-22I0-8-SI-A54

This abstract is available from: http://www.biomedcentral.com/I47I-22 I0/8/SI/A54

(c) 2008 Spiel et al; licensee BioMed Central Ltd.

\section{Background}

ARC1779 is an aptamer which blocks the A1 domain binding of the von Willebrand Factor (vWF) A1 domain to platelet glycoprotein (GP) Ib receptors. vWF is increased in the elderly and in the setting of AMI, as reflected in higher vWF levels in circulation and in increased shear-dependent platelet function as measured by the platelet function analyzer (PFA-100) and cone and plate analyzer (IMPACT). Conventional therapy of AMI partially reduces platelet activation and aggregation, but does not address excessive vWF activity or platelet adhesion.

\section{Methods}

We studied the ex vivo dose response curves for ARC1779 on PFA-100 and IMPACT platelet function tests, agonistinduced platelet aggregation, and vWF ristocetin cofactor activity (vWF:RiCO; free A1 domain sites) of patients with AMI on standard treatment including aspirin and clopidogrel $(n=40)$, young $(n=20)$ and elderly controls $(n=$ 20).

\section{Results}

AMI patients displayed $\sim 2$-fold increased plasma levels of VWF:RiCO as compared to controls. Nevertheless, the $\mathrm{IC}_{50}$ and $\mathrm{IC}_{100}$ indicate that comparable ARC1779 concentrations were needed in AMI patients and controls to sup- press vWF-dependent platelet plug formation under high sheer rates $\mathrm{IC}_{50}$ and $\mathrm{IC}_{100}$ for CADP-CT in hirudinized blood: $~ 1.6$ to $\sim 2.8 \mu \mathrm{g} / \mathrm{mL}\left(\mathrm{IC}_{50}\right.$ ) and $\sim 2.9$ to $\sim 3.9 \mu \mathrm{g} / \mathrm{mL}$ $\left(\mathrm{IC}_{100}\right)$ ). Concomitant anti-platelet therapy (aspirin and clopidogrel) in AMI patients could be responsible for this finding. In contrast to GPIIb/IIIa antagonists, ARC1779 did not inhibit platelet aggregation by ADP, collagen or arachidonic acid as measured by impedance aggregometry at concentrations $(10 \mu \mathrm{g} / \mathrm{mL})$ that fully inhibited vWFdependent platelet function.

\section{Conclusion}

ARC1779 potently and specifically inhibits vWF activity and vWF-dependent platelet function, even in the setting of AMI where vWF activity is increased. 